UCRL-JC-123285

PREPRINT

$\operatorname{CONF}-960543-10$

\title{
X-ray Backlit Imaging Measurement of In-Flight Pusher Density for an Indirect Drive Capsule Implosion
}

\author{
RECEIVED \\ D. H. Kalantar, S. W. Haan, B. A. Hammel, \\ O. L. Landen, C. J. Keane, and D. H. Munro \\ MAY 301996 \\ OSTI
}

This paper was prepared for submittal to the

11th Topical Conference on High Temperature Plasma Diagnostics

Monterey, California

May 12-16, 1996

May 6, 1996

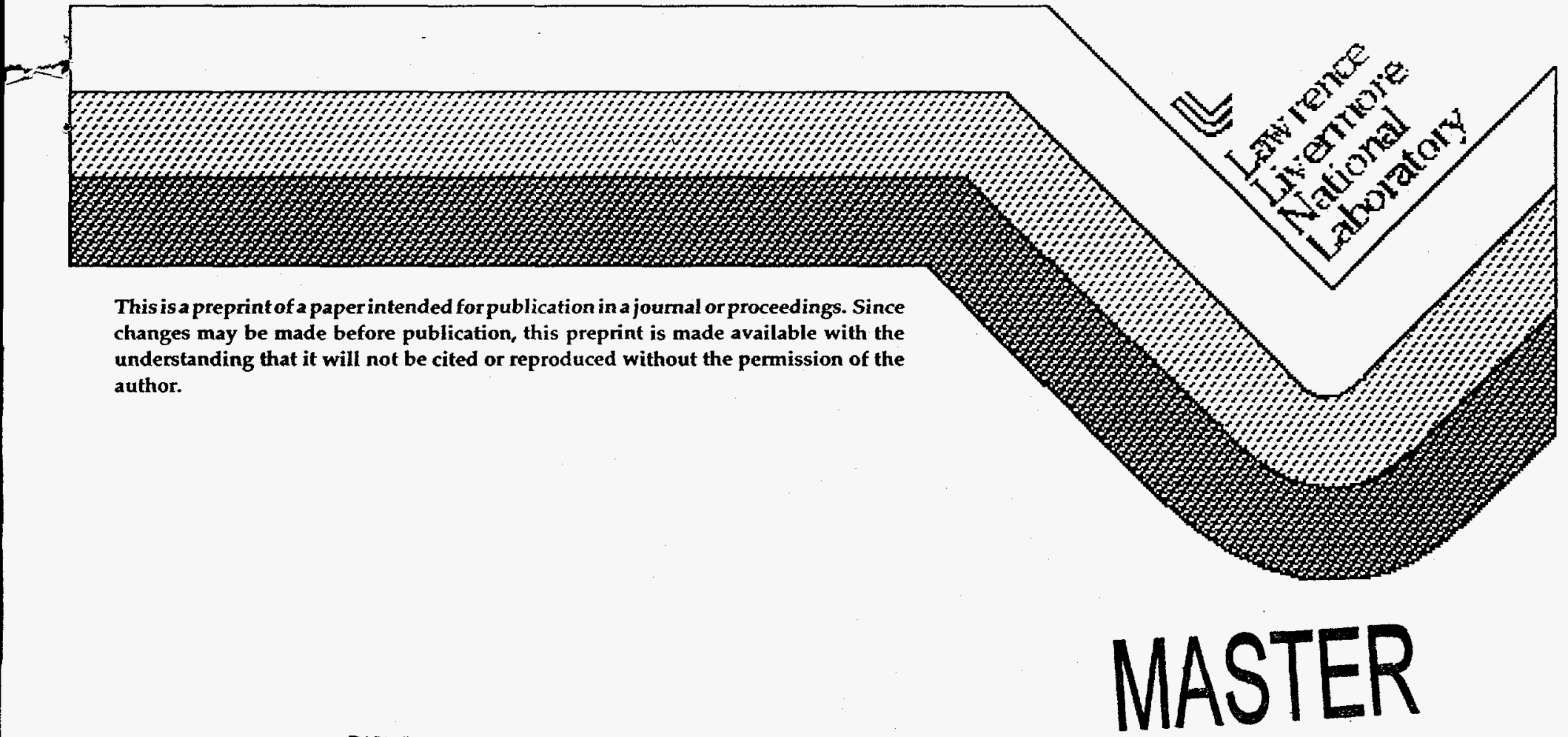




\section{DISCLAIMER}

This document was prepared as an account of work sponsored by an agency of the United States Government. Neither the United States Government nor the University of California nor any of their employees, makes any warranty, express or implied, or assumes any legal liability or responsibility for the accuracy, completeness, or usefulness of any information, apparatus, product, or process disclosed, or represents that its use would not infringe privately owned rights. Reference herein to any specific commercial product, process, or service by trade name, trademark, manufacturer, or otherwise, does not necessarily constitute or imply its endorsement, recommendation, or favoring by the United States Government or the University of California. The views and opinions of authors expressed herein do not necessarily state or reflect those of the United States Government or the University of California, and shall not be used for advertising or product endorsement purposes. 


\title{
X-ray backlit imaging measurement of in-flight pusher density for an indirect drive capsule implosion
}

\author{
D.H. Kalantar, S.W. Haan, B.A. Hammel, C.J. Keane, O.L. Landen, and D.H. Munro \\ Lawrence Livermore National Laboratory, Livermore, CA 94551
}

Both the efficiency of an implosion and the growth rate of hydrodynamic instability increase with the aspect ratio of an implosion. In order to study the physics of implosions with high Rayleigh-Taylor growth factors, we use doped ablators which should minimize $x$-ray preheat and shell decompression, and hence increase in-flight aspect ratio. We use $x$-ray backlighting techniques to image the indirectly-driven capsules. We record backlit $4.7 \mathrm{keV}$ images of the full capsule throughout the implosion phase with 55 ps and $15 \mu \mathrm{m}$ resolution. We use these images to measure the in-flight aspect ratios for doped ablators, and we inferred the radial density profile as a function of time by Abel inverting the $\mathrm{x}$-ray transmission profiles.

\section{Introduction}

In indirectly driven inertial confinement fusion (ICF) ${ }^{1}$, a fusion capsule is bathed in soft $\mathrm{x}$-rays created inside a hohlraum. The $\mathrm{x}$-ray drive ablates material from the outer capsule surface, causing the capsule to implode and compress the fuel. Both the efficiency of the implosion and the growth of hydrodynamic instabilities at the ablation surface (Rayleigh-Taylor instability) ${ }^{2}$ vary with the aspect ratio of the imploding capsule. ${ }^{3,45}$

Fuel filled capsules illuminated by a soft $x$-ray drive may suffer from preheat due to the $x$-rays. In order to maintain a low adiabat for the fuel during the implosion, it is necessary to shield the fuel from the $x$-ray drive. This is done by introducing dopants in 
the capsule ablator material. The dopant added to the ablator prevents the $x$-ray drive from preheating the capsule, and as a result, maintains a sharper density gradient and improves both the implosion efficiency and hydrodynamic instability growth.

To characterize the implosion efficiency and the hydrodynamic instability, we use $x$-ray backlighting to measure to measure the in-flight areal density of the pusher in an $x$-ray driven imploding capsule. Previous images of an indirectly driven implosion were used only to provide a measure of the implosion velocity and low-mode distortion ${ }^{6}$. We show large area backlit images that we use to perform radial intensity lineouts and to unfold a radial density profile.

\section{X-ray backlighting on Nova}

We used $x$-ray backlighting techniques ${ }^{7}$ to image an $x$-ray driven implosion capsule on the Nova laser ${ }^{8}$. We used plastic capsules that consisted of a $3 \mu \mathrm{m}$ thick polystyrene shell. They had a $3 \mu \mathrm{m}$ thick layer of polyvinyl alcohol (PVA), and a $34 \mu \mathrm{m}$ thick ablator layer coated on the outside. The overall diameter was about $510 \mu \mathrm{m}$. The ablator was a germanium-doped (Ge-doped) polystyrene with $2.5 \%$ Ge dopant, and the capsules were filled to $50 \mathrm{~atm}$ pressure with an equal mixture of hydrogen and deuterium.

The backlighter target is shown in Figure 1. The ICF capsule was placed at the center of a cylindrical gold hohlraum that was $1.6 \mathrm{~mm}$ in diameter and $2.5 \mathrm{~mm}$ long. There were two $650 \mu \mathrm{m}$ diameter diagnostic access holes in the hohlraum, positioned on opposite sides at the midplane of the hohlraum. These were covered with $150 \mu \mathrm{m}$ thick $\mathrm{CH}$ foils. A Ti backlighter disk was positioned approximately $3 \mathrm{~mm}$ from the center of the hohlraum, collinear with the capsule and diagnostic holes, and aligned to be collinear with the diagnostic line of sight for backlit imaging.

In these experiments, we used 8 beams of Nova at $0.35 \mu \mathrm{m}$ to create an $x$-ray drive in the hohlraum. The beams were pointed inside the hohlraum through the laser 
entrance holes so that they were distributed symmetrically around the azimuth of the hohlraum with a four-fold rotation symmetry. We used a $2.2 \mathrm{~ns}$ shaped laser pulse that had an intensity contrast from the foot to the peak of about 1:6 (Figure 2). A total of about $25 \mathrm{~kJ}$ of laser energy was delivered into the hohlraum, with a peak laser power of about $23 \mathrm{TW}$. The $x$-ray drive temperature in the hohlraum is shown in Figure 2. It peaks at about $200 \mathrm{eV}$ at $1.8-2.0$ ns.

We used two beams of Nova at $0.53 \mu \mathrm{m}$ for the backlighter. These were configured with random phase plates, and focused with a $\sim 700 \mu \mathrm{m}$ focal spot on the Ti backlighter foil at about $5 \times 10^{14} \mathrm{~W} / \mathrm{cm} 2$ to generate a large area $x$-ray backlighter. The laser pulse shape on these two beams was 2 ns square, which gave us a constant intensity of Ti K-shell x-rays. By using a $12 \mu \mathrm{m}$ Ti filter, the backlighter spectrum, is nearly monochromatic, principally in $4.7 \mathrm{keV}$ emission from the $1 \mathrm{~s} 2 \mathrm{p}-1 \mathrm{~s}^{2-}$ line of $\mathrm{Ti}$ (Figure 3).

We recorded radiograph images of the fusion capsule at various times during the implosion using a gated $x$-ray framing camera ${ }^{9,10}$. We adjusted the timing of the backlighter beams in order to record images over approximately $3 \mathrm{~ns}$. The camera had a full width at half maximum gate width of $55 \mathrm{ps}$. We used an array of $10 \mu \mathrm{m}$ pinholes at $8 \mathrm{X}$ magnification. We overlaid a $250 \mu \mathrm{m}$ thick collimator with $50 \mu \mathrm{m}$ diameter holes on the pinholes to limit the hard $x$-ray background in the images. In addition, the $\mathrm{CH}$ foils over the backlighter diagnostic holes were used to fill the hohlraum with low $\mathrm{Z}$ plasma and tamp the flow of gold plasma into the line of sight of the diagnostic.

\section{Backlit images of an implosion capsule}

Figure 4 shows a series of backlit images. These images are shown corrected for the diagnostic flat-field and for the spatial intensity profile of the $x$-ray backlighter.

We imaged the backlighter foil from the rear side using a second $x$-ray framing camera. The Ti backlighter foil was $12 \mu \mathrm{m}$ thick so that these images of the foil were 
filtered indentically to the backlit images of the implosion capsule. We used the flatfield characterization of the gain degradation in each stripline for both framing cameras to provide flat-field corrected images of the backlighter intensity profile and of the implosion capsule. We divided the backlit images of the implosion capsule by the spatial profile of the backlighter.

We tested that the backlit implosion images were monchromatic by measuring the tø contrast of the capsule shell. We compared the fractional transmission of backlighter $x$-rays through the center of the capsule with the unattenuated backlighter intensity. Based on the composition of the Ge-doped capsule shell, the calculated transmission through two times the total wall thickness is about 0.47 . For the image shown above in Figure $4 \mathrm{a}$, we measured a fractional transmitted intensity of 0.45 in the center of the image.

\section{In-flight pusher density profile}

The images shown in Figure 4 were obtained on two Nova target shots. For each shot, the capsule had an initial outer radius of $255 \mu \mathrm{m}$. We performed a radial lineout of each image, averaging in the azimuthal direction. For images where we had a view of unattenuated backlighter around the full azimuth, we averaged around the full $360^{\circ}$. For others where the capsule was partially ecliped by the diagnostic holes, we were limited to a smaller section of the azimuth.

We performed an Abel inversion of the radial lineouts by assuming that the capsule is spherically symmetric, and that the images are monochromatic. The resulting inversion is the product of opacity times density.

We show the inversion of one lineout at $t=1.0 \mathrm{~ns}$ in Figure 5, overlaid with results from a simulation. We used Lasnex ${ }^{11}$ to model the implosion of the Ge-doped capsule. We calculated the conditions of the pusher in the Ge-doped capsule implosions, and post-processed the Lasnex output to generate a simulated image with the backlighter 
spectrum shown in Figure 4 at a time of $1.0 \mathrm{~ns}$ into the hohlraum drive. This image was then convolved with the instrument resolution using a $10 \mu \mathrm{m}$ pinhole and unfolded by Abel inversion using the same assumptions about spherical symmetry and monochromatic imaging.

The radial lineout shown in Figure 5 is from a backlit image at $t=1.0$ ns. At this time, the sequence of images in Figure 4 shows that the outer shell starts to accelerate inward. It reaches half the initial radius at about $2.0 \mathrm{~ns}$. At $2.5 \mathrm{~ns}$, it is compressed to a radius of $50 \mu \mathrm{m}$. Note that the spatial blurring due to a framing camera gate pulse of 55 ps is $<3 \mu \mathrm{m}$ at $\mathrm{t}=1.0 \mathrm{~ns}$. At $2.0 \mathrm{~ns}$, when the radius of the shell is imploding at about $150 \mu \mathrm{m}$ per $\mathrm{ns}$, the spatial blurring is $8 \mu \mathrm{m}$.

The shock preheated ablator is $<<100 \mathrm{eV}$. As a result, the opacity of the Gedoped ablator material ( $\mathrm{L}$-shell Ge and $\mathrm{K}$-shell carbon) is nearly identical to the cold material opacity at the backlighter energy of $4.7 \mathrm{keV}$. If we divide the Abel inverted lineouts by the cold opacity for Ge-doped polystyrene, then these lineouts represent the density profile of the capsule pusher. They provide a measurement of the radius and the aspect ratio as a function of time. We plot the radial density profile calculated by Abel inversion for several times in Figure 6. Note that we have smoothed the inverted lineouts at small radius. The azimuthal average smooths the radial lineout at large radius, but we are dominated by the noise statistics and speckle of the backlighter profile at small radius.

We measured the radius of the half maximum density on the outer edge of the Abel-inverted lineouts. This is shown in Figure 7, plotted with the aspect ratio which we calculate as the average radius to the full width at half maximum of the radial density profile for each time. The hohlraum drive temperature is also shown in the graph for timing. 


\section{Summary}

We have used $x$-ray backighting techniques to record images of an indirectly driven ICF capsule on Nova. These large area images of the full capsule provide quantitative information about the in-flight pusher density profile as a function of time. This technique may be used to characterize the in-flight aspect ratio of capsules, providing information about the efficiency and hydrodynamic instability of an implosion.

\section{Acknowledgments}

We acknowledge the support of the diagnostic development group at Nova and the collaboration of D. Bradley of Rochester in developing the fast framing camera we : used for these experiments. This work was performed under the auspices of the U.S. Department of Energy by the Lawrence Livermore National Laboratory under Contract No. W-7405-ENG-48. 


\section{List of figures}

Figure 1: Diagram of the backlighter target used on Nova.

Figure 2: Laser power and hohlraum x-ray drive temperature as a function of time.

Figure 3: Titanium x-ray backlighter spectrum..

Figure 4: Series of $x$-ray backlit images of a Ge-doped capsule recorded at $t=0.0,1.0$, 1.5, 2.0, and $2.5 \mathrm{~ns}$. The scales are in microns at the target.

Figure 5: Abel inversion of a single radial lineout of the measured $x$-ray transmission through the capsule at $t=1.0$ ns. This is compared with a radial lineout from postprocessed Lasnex output..

Figure 6: Radial density profiles calculated by Abel inverting radial lineouts of the $x$ ray transmission through the capsule.

Figure 7: Radius and aspect ratio of the capsule as a function of time. The x-ray drive temperature is shown as well. 


\section{References}

'J. Lindl, Phys.Plasmas 2, 3933 (1995).

${ }^{2}$ Lord Rayleigh, Scientific Papers Vol. II, P, 200, Cambridge Univ. Press (1900).

${ }^{3}$ O. L. Landen, C. J. Keane, B. A. Hammel, W. K. Lovedahl, P. A. Amendt, J. D. Colvin,

M. D. Cable, R. Cook, T. R. Dittrich, S. W. Haan, S. P. Hatchett, R. G. Hay, R. A. Lerche, R. McEachern, T. J. Murphy, M. B. Nelson, L. Suter, and R. J. Wallace, "Effects of variable $x$-ray preheat shielding in indirectly-driven implosions", to appear in Phys. Plasmas.

${ }^{4}$ O. L. Landen, C. J. Keane, B. A. Hammel, M. D. Cable, J. D. Colvin, R. Cook, T. R. Dittrich, S. W. Haan, S. P. Hatchett, R. G. Hay, J. D. Kilkenny, R. A. Lerche, W. K. Lovedahl, R. McEachern, T. J. Murphy, M. B. Nelson, L. Suter, and R. J. Wallace, J. Quant. Spectrosc. Radiat. Trasfer 54, 245 (1995).

${ }^{5}$ C. Keane, G. W. Pollak, R. C. Cook, T. R. Dittrich, B. A. Hammel, O. L. Landen, S. H. Langer, W. K. Lovedahl, D. H. Munro, H. A. Scott, and G. B. Zimmerman, J. Quant. Spectrosc. Radiat. Transfer 54, 207 (1995).

${ }^{6}$ M. Katayama, H. Shiraga, M. Nakai, T. Kobayashi, and Y. Kato, Rev. Sci. Instrum. 64, 706 (1993).

${ }^{7}$ S. G. Glendinning, P. Amendt, K. S. Budil, B. A. Hammel, D. H. Kalantar, M. H. Key, O. L. Landen, B. A. Remington, and D. E. Desenne, in Applications of Laser Plasma Radiation II, edited by M. C. Richardson and G. A. Kyrala (SPIE, Bellingham, WA, 1995), Vol. 2523, pp. 29-39.

${ }^{8}$ E. M. Campbell, J. T. Hunt, E. S. Bliss, D. R. Speck, and R. P. Drake, Rev. Sci. Instrum. 57, 2101 (1986).

${ }^{9}$ D. K. Bradley, P. M. Bell, O. L. Landen, J. D. Kilkenny, and J. Oertel, Rev. Sci. Instrum. 66, 716 (1995). 
${ }^{10}$ P. M. Bell, J. D. Kilkenny, O. L. Landen, D. K. Bradley, R. Watt, and J. Oertel, in Ultrahigh and High Speed Photography, Videography, and Photonics '94 (SPIE, Bellingham, WA, 1994), p. 234, 1994.

${ }^{11}$ G. B. Zimmerman and W. L. Kruer, Comments Plasma Phys. Controlled Fusion 2, 51 (1975). 


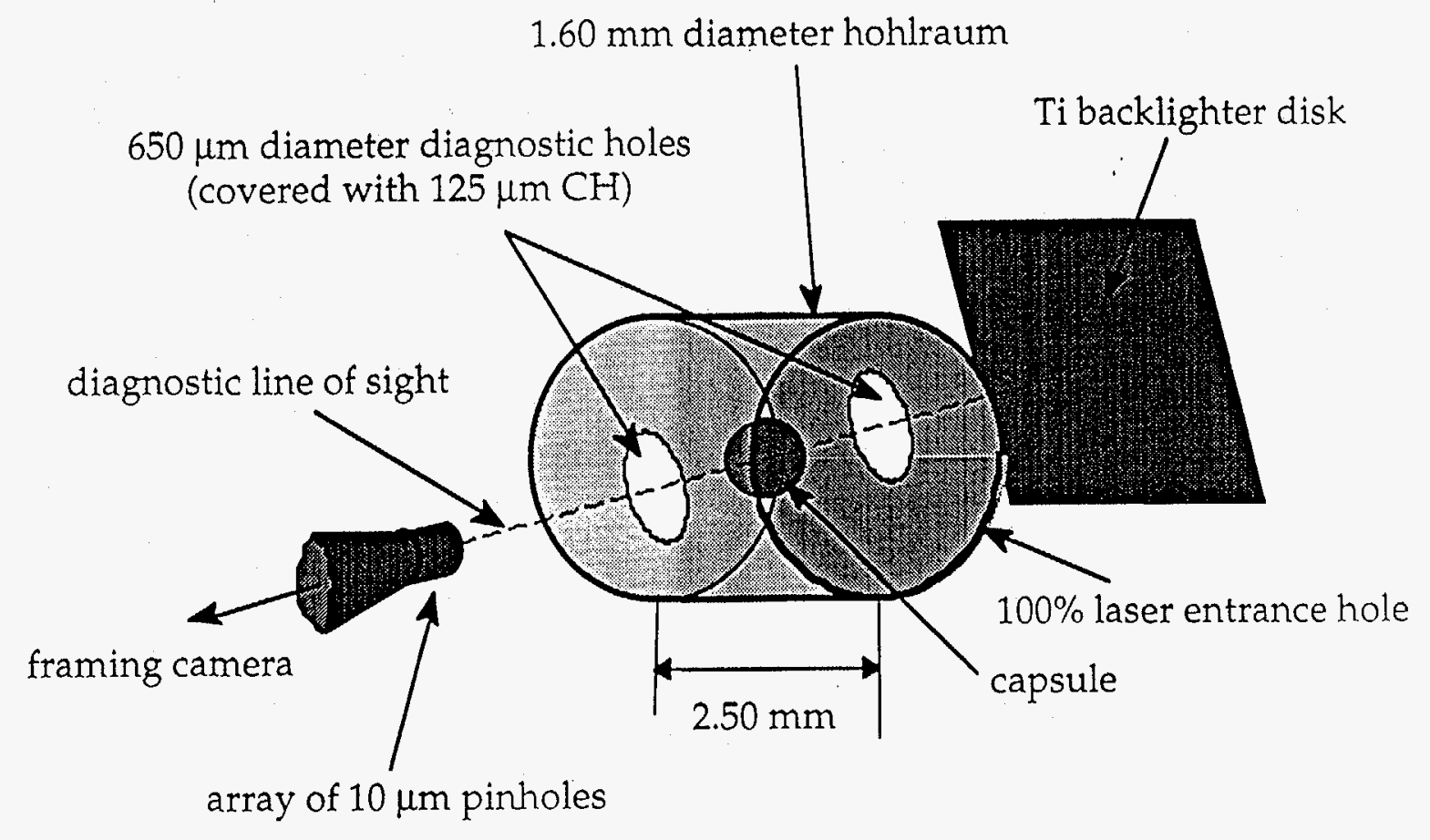

Figure 1: Diagram of the backlighter target used on Nova. 
Hohlraum drive temperature $(\mathrm{eV})$

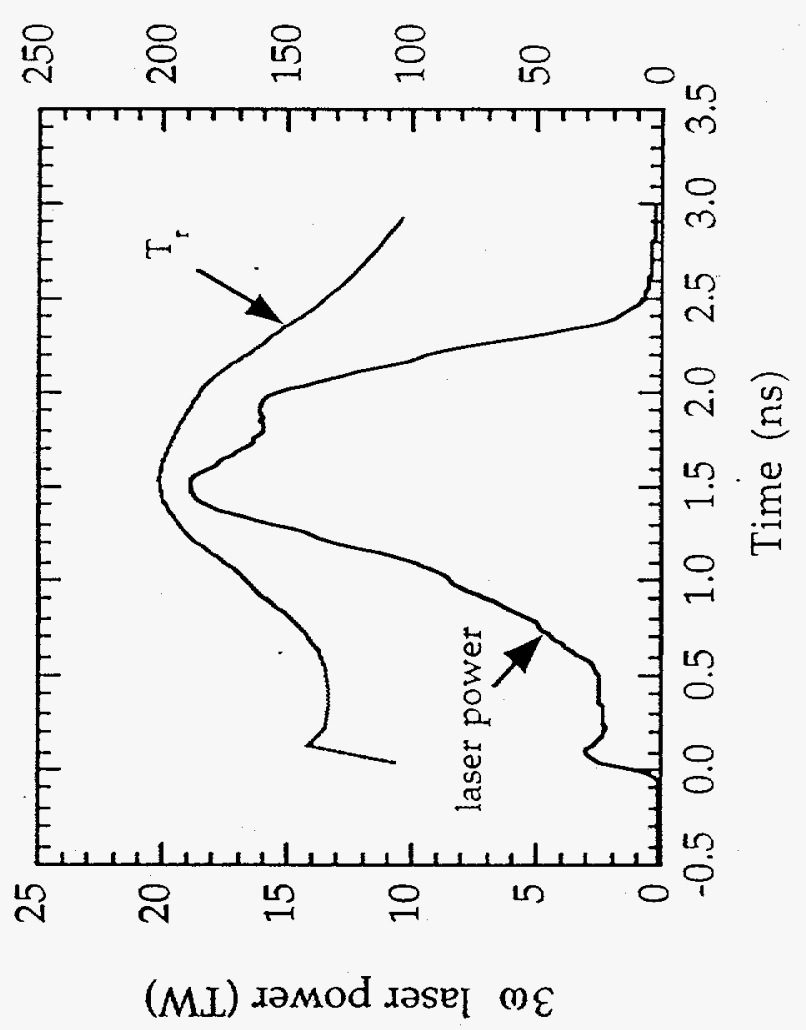




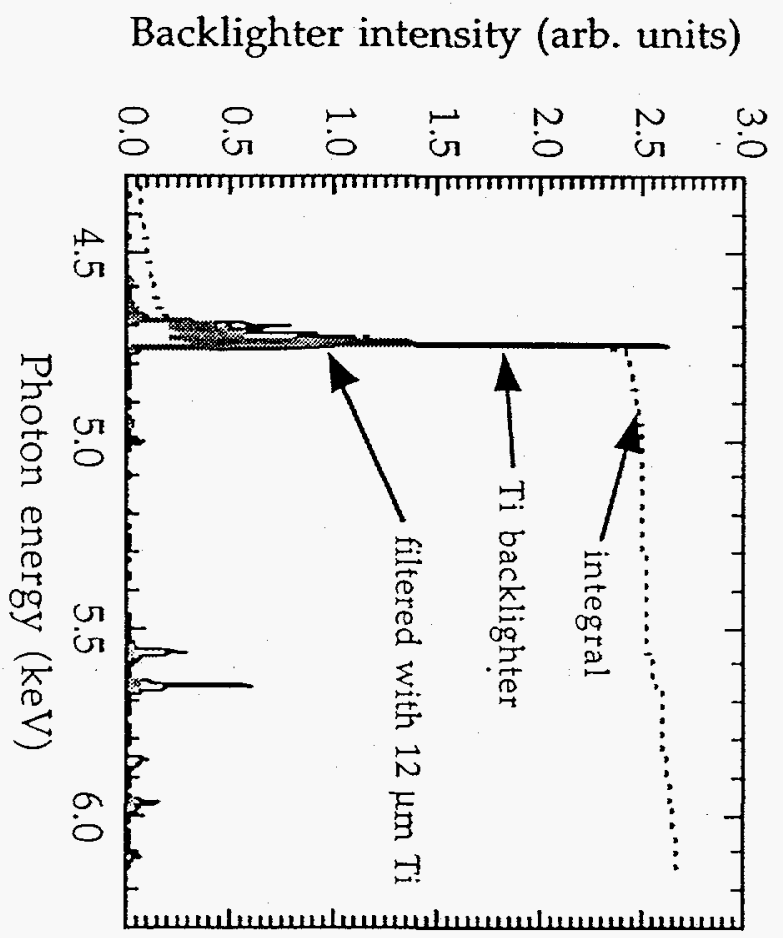




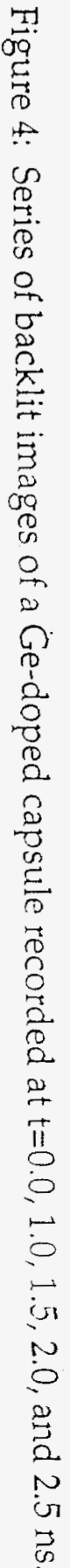
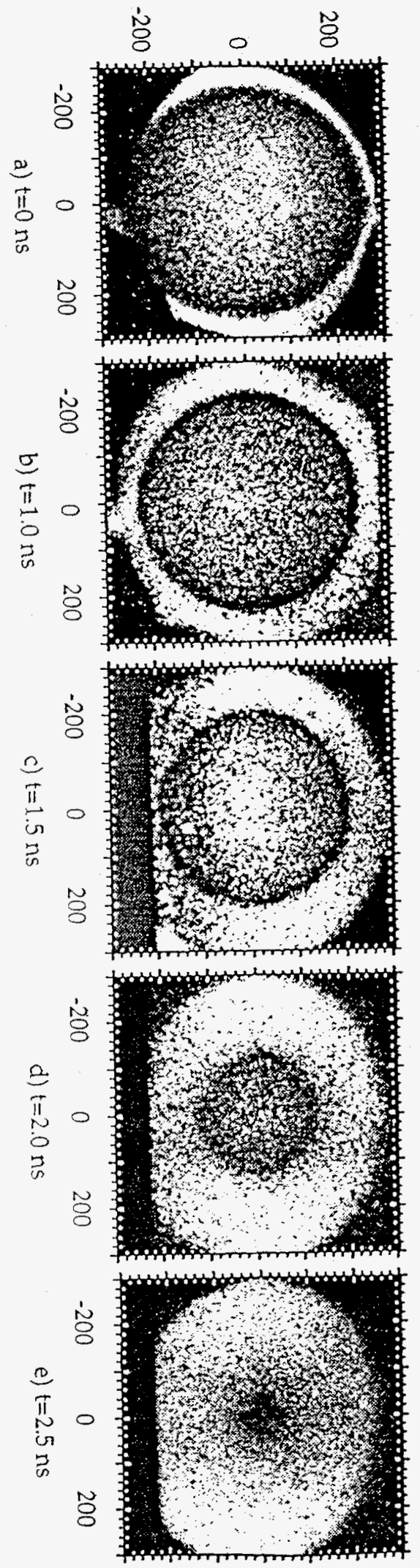
Fractional transmission

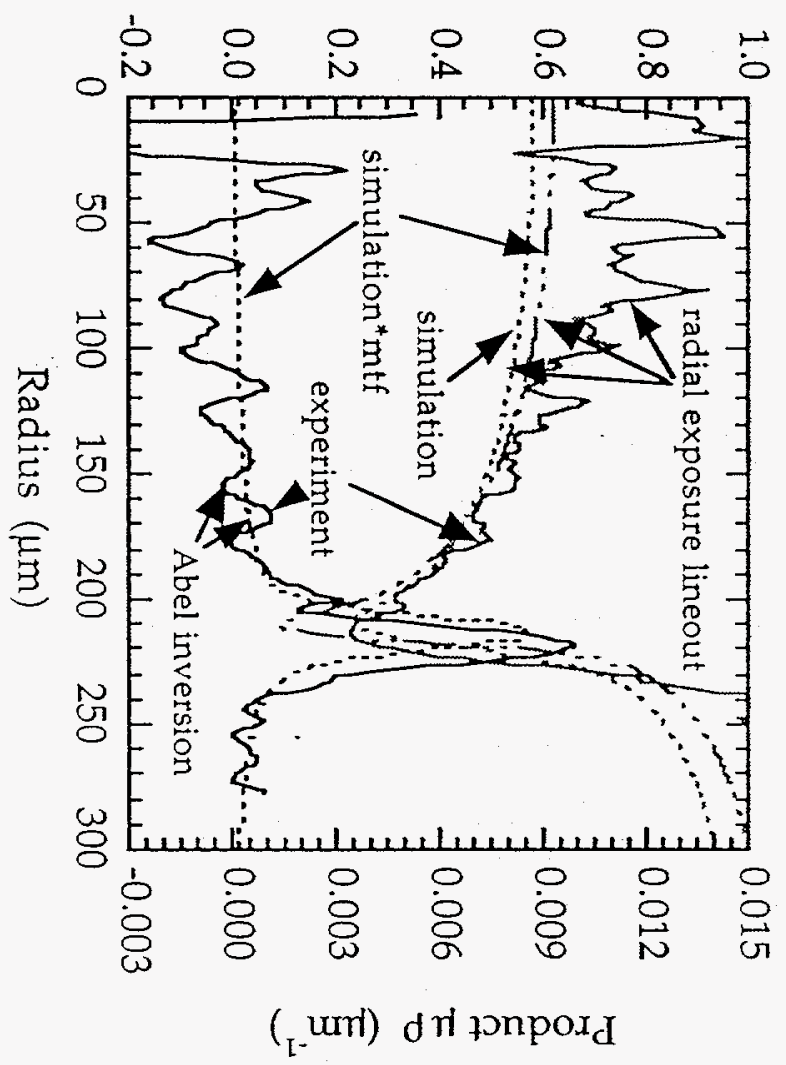




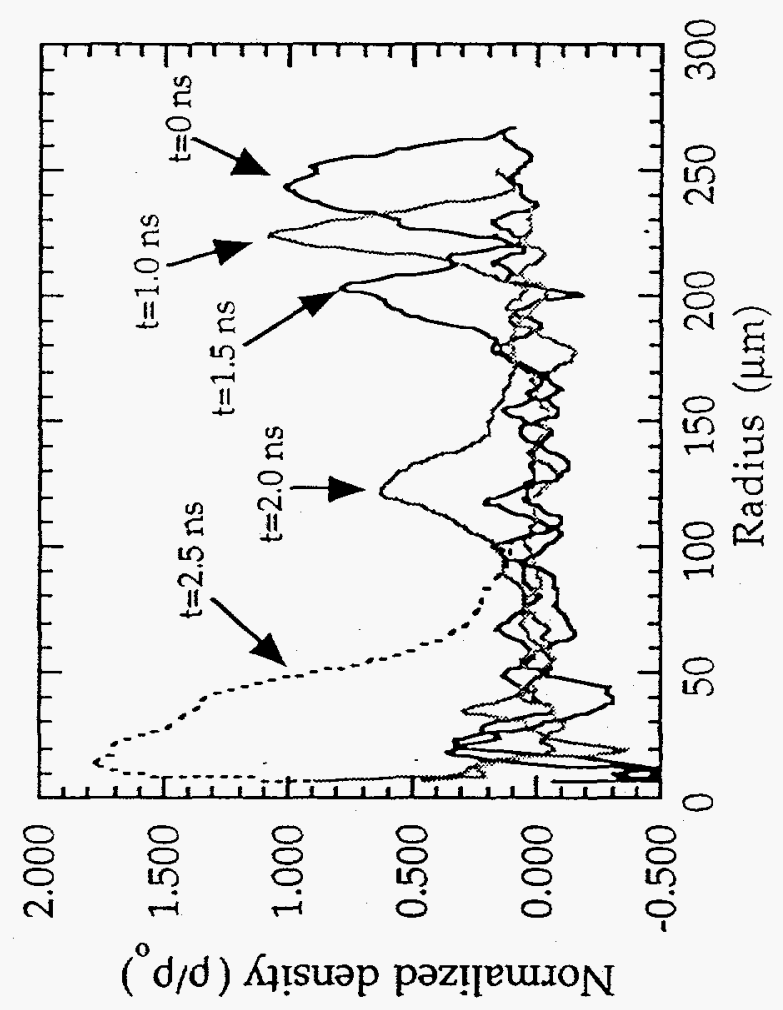

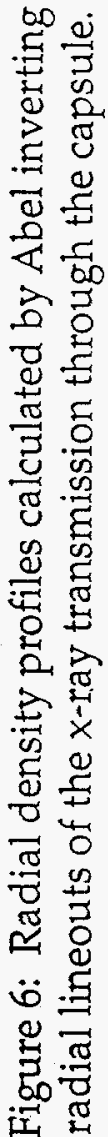




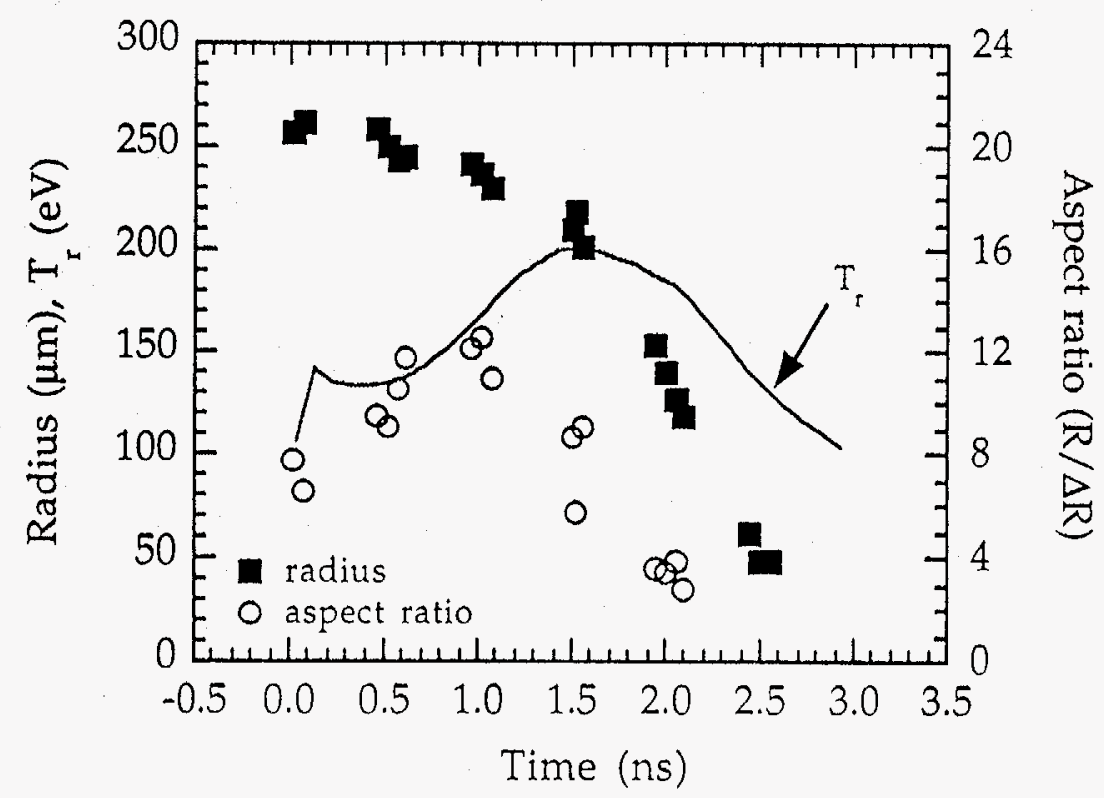

Figure 7: Radius and aspect ratio of the capsule as a function of time. The $x$-ray drive temperature is shown as well. 


$$
1
$$

